\title{
Electrochemical Synthesis of Allylic Amines from Alkenes and Amines
}

\author{
Diana J. Wang, Karina Targos, and Zachary K. Wickens* \\ Department of Chemistry, University of Wisconsin-Madison, Madison, Wisconsin 53706, United States
}

\begin{abstract}
Allylic amines are valuable synthetic targets en route to diverse biologically active amine products. Current allylic C-H amination strategies remain limited with respect to the viable $N$-substituents. Herein we disclose a new electrochemical process to prepare aliphatic allylic amines by coupling two abundant starting materials: secondary amines and unactivated alkenes. This oxidative transformation proceeds via electrochemical generation of an electrophilic adduct between thianthrene and the alkene substrates. Treatment of these adducts with aliphatic amine nucleophiles and base provides allylic amine products in high yield. This synthetic strategy is also amenable to functionalization of feedstock gaseous alkenes at 1 atmosphere. In the case of 1-butene, remarkable Z-selective crotylation is observed. This strategy, however, is not limited to the synthesis of simple building blocks; complex biologically active molecules are suitable as both alkene and amine coupling partners. Preliminary mechanistic studies implicate vinylthianthrenium salts as key reactive intermediates.
\end{abstract}

Aliphatic amines are prevalent in pharmaceuticals, natural products, and other biologically active molecules. ${ }^{1-3}$ Thus, the development of strategies to rapidly construct $\mathrm{C}-\mathrm{N}$ bonds is of longstanding synthetic importance. Allylic amines are particularly valuable building blocks due to their synthetic versatility. ${ }^{4-8}$ A deceptively simple strategy to prepare alkyl allylic amines would be the oxidative coupling of alkenes and aliphatic amines (Fig. 1, top). Such a reaction would be an attractive complement to classic amine allylation strategies such as $\mathrm{S}_{\mathrm{N}} 2^{9-16}$ and $\pi$-allyl substitution reactions ${ }^{17-24}$ that rely on prefunctionalized electrophiles. However, successful realization of such a transformation requires a strategy to promote the desired oxidative $\mathrm{C}-\mathrm{N}$ bond-forming process without undesired oxidation of the aliphatic amine starting materials or the aliphatic allylic amine products $\left(0.8-1.1 \mathrm{~V}\right.$ vs SCE).$^{25}$ As a consequence, generation of aliphatic allylic amines by oxidative coupling of alkenes and amines has remained elusive. ${ }^{26-35}$ Instead, pioneering reports have established powerful $\mathrm{C}-\mathrm{H}$ functionalization protocols to construct allylic $\mathrm{C}-\mathrm{N}$ bonds using oxidatively stable nitrogen sources. ${ }^{36-39}$ These reaction manifolds primarily take advantage of electronically deactivated nitrogen pronucleophiles ${ }^{40-50}$ and nitrene precursors ${ }^{51-65}$ As a direct result, these established approaches offer limited access to aliphatic allylic amine products and instead furnish products with electron-deficient nitrogen atoms, such as allylic sulfonamides and carbamates (Fig. 1, middle).

Despite the significant progress in other oxidative amination reactions, ${ }^{66-71}$ to date, there is a single intermolecular allylic $\mathrm{C}-\mathrm{H}$ amination reaction that directly furnishes aliphatic allylic amine products. ${ }^{26}$ This strategy, reported by Ritter and co-workers in 2020, exploits photochemicallyactivated sulfilimine reagents as nitrogen sources. While this is a landmark report in allylic $\mathrm{C}-\mathrm{H}$ amination, installation of different $N$-substituents in the product requires preparation of unique electrophilic reagents. Additionally, this reagent design strategy is not readily amenable to tertiary amine synthesis.

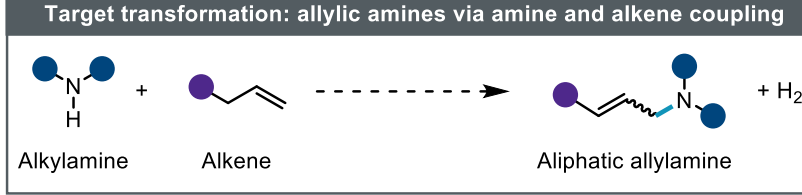

Established oxidative allylic amination methods
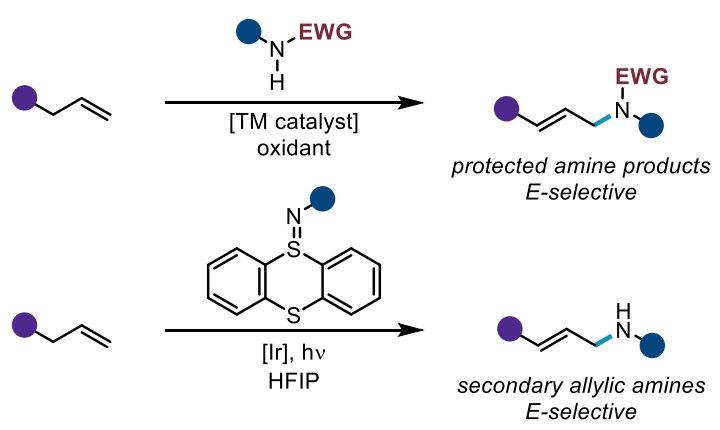

This work: electrochemical synthesis of allylic amines TT

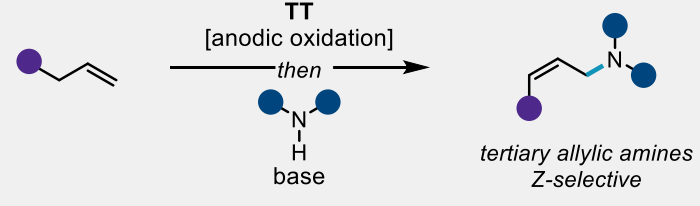

Figure 1. Project overview. Idealized transformation to access alkyl allylic amines (top); representative established allylic $\mathrm{C}-\mathrm{H}$ amination reactions (middle); schematic overview of this work (bottom). TT = thianthrene.

Accordingly, a complementary synthetic technology that generates allylic amines via an oxidative coupling of unactivated amine nucleophiles and alkenes remains poised to have a significant impact on organic synthesis. Such an approach would directly translate the $>4$ million commercially available aliphatic amines into versatile allylic amine building blocks. ${ }^{72}$ 


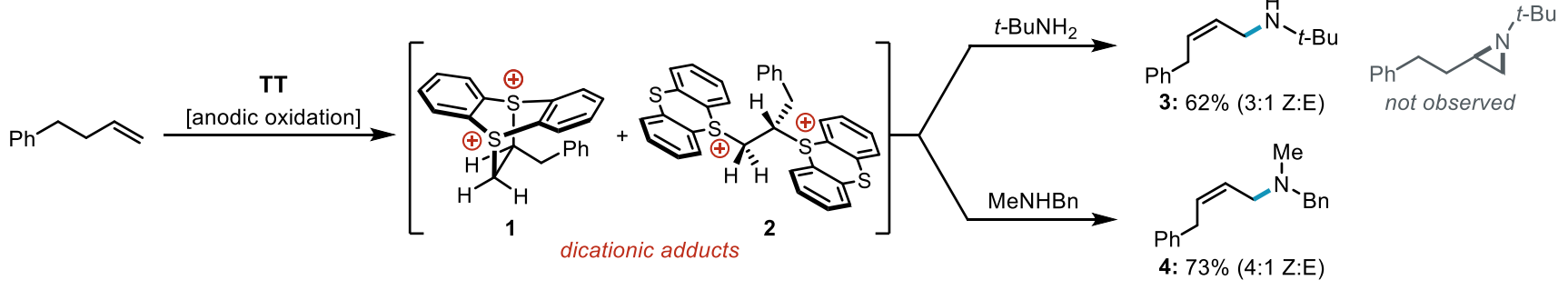

${ }^{a}$ Reactions were conducted using alkene $(0.15 \mathrm{mmol})$, TT $(0.23 \mathrm{mmol}), 3 \mathrm{~mL} \mathrm{MeCN}\left(0.2 \mathrm{M} n\right.$-Bu $\left.\mathrm{NPF}_{6}\right), \mathrm{I}=4.0 \mathrm{~mA}, 2.5 \mathrm{~h}\left(2.5 \mathrm{~F}\right.$ mol ${ }^{-1}$ alkene); then amine $(1.2$ $\mathrm{mmol}), 16 \mathrm{~h}$. Yields and Z:E ratios were determined by ${ }^{1} \mathrm{H}$ NMR analysis. See the Supporting Information (SI) for details.

We recently developed an electrochemical strategy to engage oxidatively sensitive nucleophiles in net oxidative alkene difunctionalization reactions. ${ }^{71}$ Our approach draws inspiration from Yoshida's pioneering cation pool work ${ }^{73-75}$ and contributes to a rapidly growing body of literature exploiting oxidized thianthrene derivatives as synthetic intermediates. ${ }^{76-83}$ Specifically, we leveraged electrochemistry to cleanly generate dicationic adducts between unactivated alkenes and thianthrene (TT), ${ }^{84,85}$ a safe ${ }^{86}$ and inexpensive ${ }^{87}$ reagent. This strategy circumvents the need for oxidatively stable coupling partners in net oxidative alkene functionalization reactions; the oxidative alkene activation event is decoupled from nucleophilic substitution. In our first report, we leveraged this approach to enable the formal coupling of primary amine nucleophiles with alkenes to furnish aziridine products through a one-pot, two-operation process. Herein, we report an electrochemical strategy to prepare linear, tertiary allylic amine products with Z-selectivity from aliphatic amines and alkenes. This is accomplished by diverting the reactivity of the dicationic alkene-thianthrene adducts down a formal substitutionelimination pathway.

Our development of an allylic amination process began with an unexpected observation during the study of our dication pool aziridination reaction. We found that, upon exposure to excess tert-butylamine, the electrogenerated mixture of dicationic electrophiles $\mathbf{1}$ and $\mathbf{2}$ was transformed into the linear allylic amine product 3 in 3:1 Z:E ratio rather than the expected $N$-tert-butylaziridine (Scheme 1). We suspected this net substitution-elimination process may be a consequence of the increased steric bulk about the nitrogen nucleophile. This rationalization suggested that secondary amine nucleophiles may proceed down an analogous allyic amination pathway rather than forming aziridinium intermediates. Such a reaction would furnish tertiary ( $\mathrm{Z}$ )-allylic amine products and serve as an ideal complement to the recent secondary (E)-allylic amine synthesis developed by Ritter and co-workers. ${ }^{26}$ To probe this hypothesis, we exposed an electrogenerated mixture of $\mathbf{1}$ and $\mathbf{2}$ to an excess of $N$-methylbenzylamine. To our delight, this resulted in conversion of the adduct to the corresponding allylic amine product 4 with 4:1 Z-selectivity. Next, we aimed to identify a suitable stoichiometric base to lower the necessary equivalents of amine (Table 1). We surveyed a range of bases and found $i-\mathrm{Pr}_{2} \mathrm{NEt}$ promoted the desired allylic functionalization in $79 \%$ yield with a 1:1 stoichiometry of amine and alkene starting materials. Increasing the steric bulk of the amine base to triisobutylamine resulted in formation of a vinyl thianthrenium salt $\mathbf{5}$ alongside a reduced yield of allylic amine product (entry 2). Smaller amine bases, such as triethylamine, also resulted in reduced yield $(40 \%)$ of the desired allylic amine product 4 due to competitive formation of an allylic ammonium salt $\mathbf{6}$ derived from the triethylamine base (entry
3). Alternative bases, such as $\mathrm{Cs}_{2} \mathrm{CO}_{3}$, promoted the desired Table 1. Base evaluation for the allylic amination reaction. ${ }^{a, b}$

\begin{tabular}{|c|c|c|c|}
\hline \multirow[b]{3}{*}{ entry } & \multicolumn{2}{|c|}{$\begin{array}{c}\text { TT } \\
\text { [anodic oxidation] }\end{array}$} & \\
\hline & \multicolumn{2}{|c|}{$\begin{array}{c}\text { MeNHBn } \\
\text { [base] }\end{array}$} & \\
\hline & base & yield 4 (Z:E) & yield $\mathbf{5}$ \\
\hline 1 & $i-\mathrm{Pr}_{2} \mathrm{NEt}$ & $79 \%(6: 1)$ & n.d. \\
\hline 2 & $i-\mathrm{Bu}_{3} \mathrm{~N}$ & $27 \%(5: 1)$ & $52 \%^{c}$ \\
\hline 3 & $\mathrm{Et}_{3} \mathrm{~N}$ & $40 \%(3: 1)$ & n.d. \\
\hline 4 & $\mathrm{Cs}_{2} \mathrm{CO}_{3}$ & $61 \%(3: 1)$ & n.d. \\
\hline 5 & $\mathrm{NaHCO}_{3}$ & $<5 \%$ & $67 \%^{d}$ \\
\hline
\end{tabular}

Observed side products
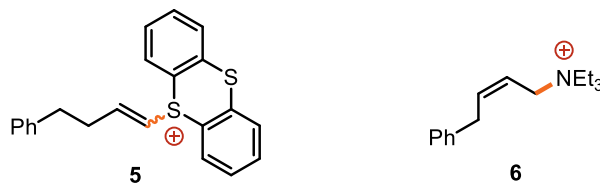

${ }^{a}$ Reactions were conducted using alkene $(0.15 \mathrm{mmol})$, TT $(0.23 \mathrm{mmol}), 3 \mathrm{~mL}$

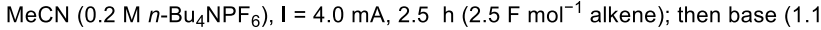
$\mathrm{mmol})$, amine $(0.30 \mathrm{mmol}), 16 \mathrm{~h}$. Yields and $\mathrm{Z}$ : $E$ ratios were determined by ${ }^{1} \mathrm{H}$ NMR analysis. See the Supporting Information (SI) for details. ${ }^{b}$ n.d. = not detected. ${ }^{c} 5: 1 \mathrm{E}: Z$ ratio. ${ }^{d} 6: 1 \mathrm{E}: Z$ ratio.

allylic functionalization albeit in diminished $Z$-selectivity (entry 4). Weaker inorganic bases, such as $\mathrm{NaHCO}_{3}$, provided vinyl thianthrenium product alongside traces of the desired allylic amine (entry 5). Overall, this method provides an appealing one-pot synthesis of allylic amine building blocks.

With optimized conditions in hand, we next investigated the alkene scope for this allylic amination process, employing $\mathrm{N}$-methylbenzylamine as a model secondary amine nucleophile (Table 2). Allylic amination of 4-phenyl-1-butene and an aryl bromide derivative provided the desired (Z)-allylic amine products $(\mathbf{4}, \mathbf{7})$ without detectable arene thianthrenation. Likewise, selective alkene functionalization in the presence of an unconjugated alkyne was obtained with high Z-selectivity (8). This result, alongside with tolerance of aromatic substrates $(4,7)$, illustrates the exquisite chemoselectivity for adduct formation between oxidized thianthrene and alkene over previously observed thianthrenation of arenes ${ }^{76}$ and alkynes. ${ }^{88}$ Unconjugated dienes underwent selective monofunctionalization to provide a (Z)-skipped diene 9 and (E)-conjugated diene 10 building blocks. Alkenes bearing a variety of proximal functional groups, such as nitrile (11), acetate (12), ether (13), and phthalimide (14) each efficiently delivered the desired allylic amine products. These examples illustrate the viability of accessing allylic amine building blocks with a secondary homoallylic $(\mathbf{1 1}, \mathbf{1 2})$ or allyic $(\mathbf{1 3}, \mathbf{1 4})$ functional group handle for further elaboration. Allylcyclohexane underwent allylic 
Table 2. Scope of alkenes for allylic amination via dication pool strategy. ${ }^{a, b}$ TT

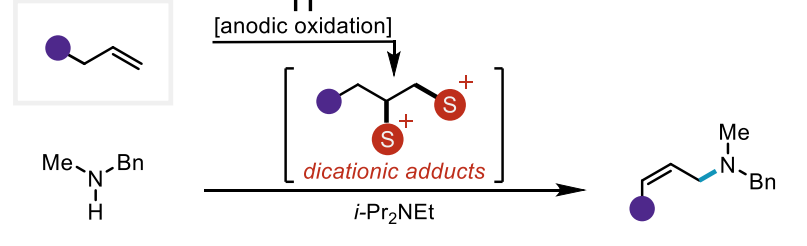

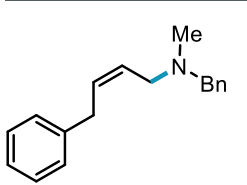

4: $67 \%(5: 1)$<smiles>C=CC/C=C\CN(C)Cc1ccccc1</smiles>

9: $69 \%(5: 1)$<smiles>CC(=O)OC/C=C\CCN(C)[Sn]</smiles>

12: $66 \%(4: 1)$

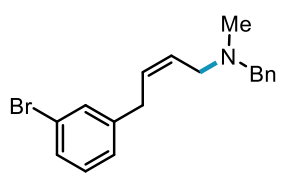

7: $73 \%(5: 1)$<smiles>C=C/C=C/CN(C)Cc1ccccc1</smiles>

10: $57 \%{ }^{c}(1: 3)$<smiles>CN(C/C=C\COc1ccccc1)Cc1ccccc1</smiles>

13: $52 \%(2: 1)$

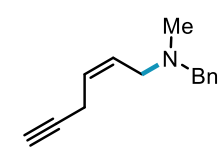

8: $60 \%(>20: 1)$<smiles>[N+]=CCC/C=C\C[NH+]=[N+]</smiles>

11: $77 \%(3: 1)$

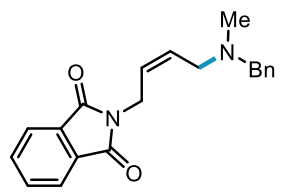

14: $63 \%^{c}(2: 1)$<smiles>CC1CCC(/C=C\CN(C)Cc2ccccc2)CC1</smiles>

15: $58 \%(2: 1)$<smiles>CN(CC=C1CCCCC1)Cc1ccccc1</smiles>

16: $53 \%$

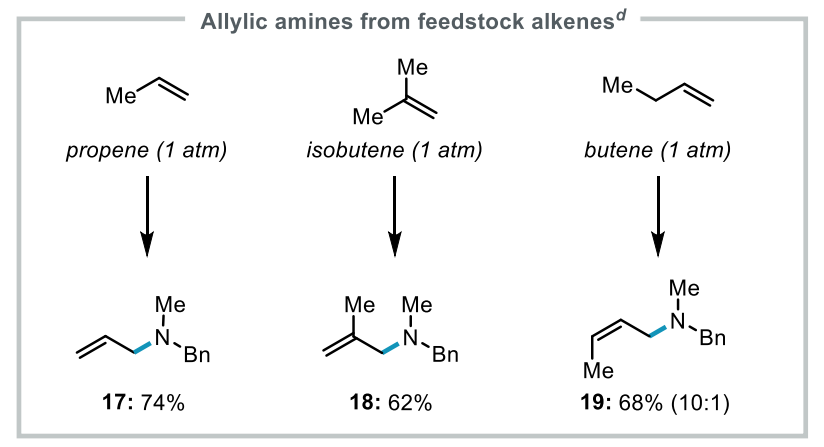

${ }^{a}$ Reactions were conducted using alkene $(0.4 \mathrm{mmol})$, TT $(0.6 \mathrm{mmol}), 8 \mathrm{~mL}$

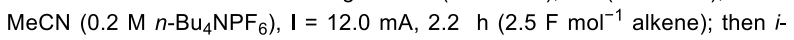
$\mathrm{Pr}_{2} \mathrm{NEt}(2.8 \mathrm{mmol})$, amine $(0.8 \mathrm{mmol}), 16 \mathrm{~h}$. Yields and $\mathrm{Z}$ : $\mathrm{E}$ ratios are of the purified product unless otherwise noted. See the $\mathrm{SI}$ for further details. ${ }^{b}$ Isolated yield (Z:E). ${ }^{c} \mathrm{NMR}$ yield. ${ }^{d}$ Reactions were conducted using alkene (1

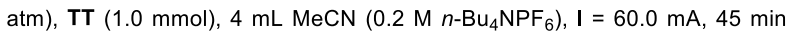
(1.7 $\left.\mathrm{F} \mathrm{mol}^{-1} \mathrm{TT}\right)$; then $i-\mathrm{Pr}_{2} \mathrm{NEt}(3.2 \mathrm{mmol})$, amine $(0.4 \mathrm{mmol}), 3 \mathrm{~h}$.

amination to furnish the sterically hindered vinylcyclohexane product 15. ${ }^{89}$ Finally, vinylcyclohexane underwent allylic amination to form trisubstituted allylic amine $\mathbf{1 6} .{ }^{90}$

We next probed whether this oxidative coupling strategy is also amenable to functionalization of commodity feedstock alkenes derived from steam cracking and related petroleum refinery processes (Table 2). ${ }^{91,92}$ Electrolysis of thianthrene under one atmosphere of propene and isobutene each generated the desired dicationic adducts. Treatment of these reaction mixtures with $i$ - $\operatorname{Pr}_{2} \mathrm{NEt}$ and $\mathrm{N}$ methylbenzylamine resulted in allyl- and methallylamine products $(\mathbf{1 7}, \mathbf{1 8})$ in high yields relative to the amine starting

material. Traditional methods to produce these products rely on $\mathrm{S}_{\mathrm{N}} 2$ displacement of the corresponding allylic halides, which are industrially derived from the same feedstock alkenes through a multistep oxidation-halogenation sequence. ${ }^{93}$ In contrast, this electrochemical method offers an appealing alternative protocol that produces $\mathrm{H}_{2}$ gas as the stoichiometric byproduct since thianthrene can be recycled and reused.$^{94}$ Notably, 1-butene-the simplest alkene to form stereoisomeric allylic amine products - gave allylic amine $\mathbf{1 9}$ in high Zselectivity. This highlights the value of this new transformation beyond a green chemistry context; crotylhalides are only readily available as an $€$-dominant mixture.

Next, we probed the scope of the amine nucleophile, employing 1-butene as the alkene coupling partner (Table 3). These transformations furnish synthetically attractive Zcrotylamine building blocks that are not straightforward to access using conventional alkylation chemistry. Simple, acyclic dialkylamines (20-23) resulted in high yields and Zselectivity. Of note, even sterically hindered amines delivered the corresponding Z-crotylamine product 21, albeit with a diminished yield. Heteroaromatic and saturated heterocycles are tolerated both as pendant functional groups $(\mathbf{2 2}, \mathbf{2 3})$ or as the nucleophile itself (24-28). Amine nucleophiles bearing potential competing nucleophiles were also selectively transformed into $(Z)$-allylic amine products $(\mathbf{2 4 , 2 6})$, preserving the unprotected functional groups for further derivatization. In addition to spirocyclic piperidine (24), other bicyclic heterocycles with morpholine (27) and piperazine (28) cores underwent $Z$-selective crotylation.

In addition to the efficient formation of simple, allylic amine building blocks, we envisioned that this newly realized oxidative allylic amination methodology would also streamline the synthesis of more complex amine products (Table 4). With this in mind, we next evaluated a range of drug-

Table 3. Scope of Z-crotylamine building blocks. ${ }^{a, b}$
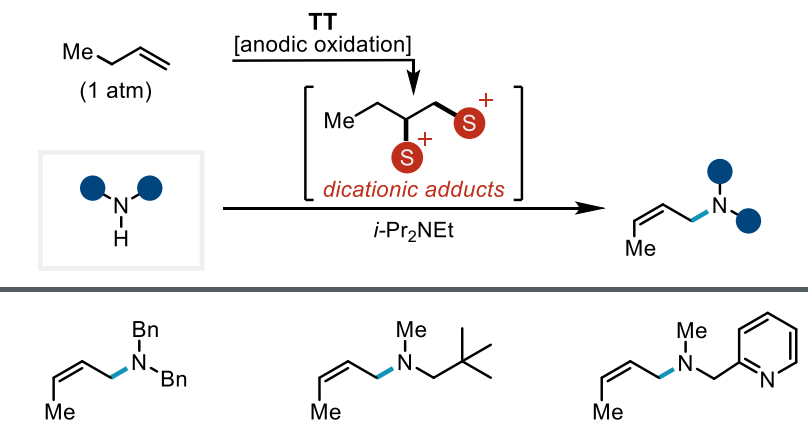

20: $71 \%(10: 1)$

21: $38 \%^{c}(10: 1)$

22: $62 \%^{c}(9: 1)$<smiles>C/C=C\CN(C)C1CCN(C(C)(C)C)CC1</smiles>

23: $56 \%^{\mathrm{c}}(9: 1)$

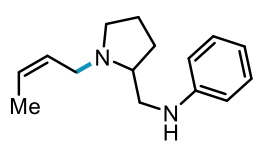

26: $73 \%(>20: 1)$

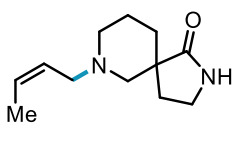

24: $85 \%(>20: 1)$

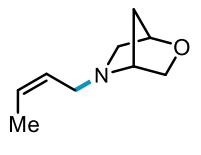

27: $53 \%(9: 1)$

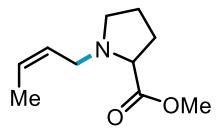

25: $62 \%(10: 1)$

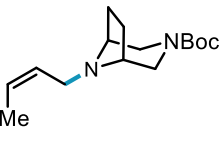

28: $80 \%(12: 1)$
${ }^{a}$ Reactions were conducted using butene (1 atm), TT $(1.0 \mathrm{mmol}), 4 \mathrm{~mL} \mathrm{MeCN}$

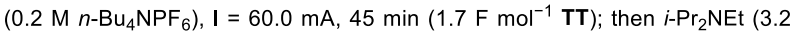
$\mathrm{mmol})$, amine $(0.4 \mathrm{mmol}), 3 \mathrm{~h}$. Yields and $\mathrm{Z}: \mathrm{E}$ ratios are of the purified product unless otherwise noted. See the SI for further experimental details. ${ }^{b}$ Isolated yield (Z:E). ${ }^{C} \mathrm{NMR}$ yield. 
Table 4. Oxidative coupling of complex bioactive molecules. ${ }^{a, b}$
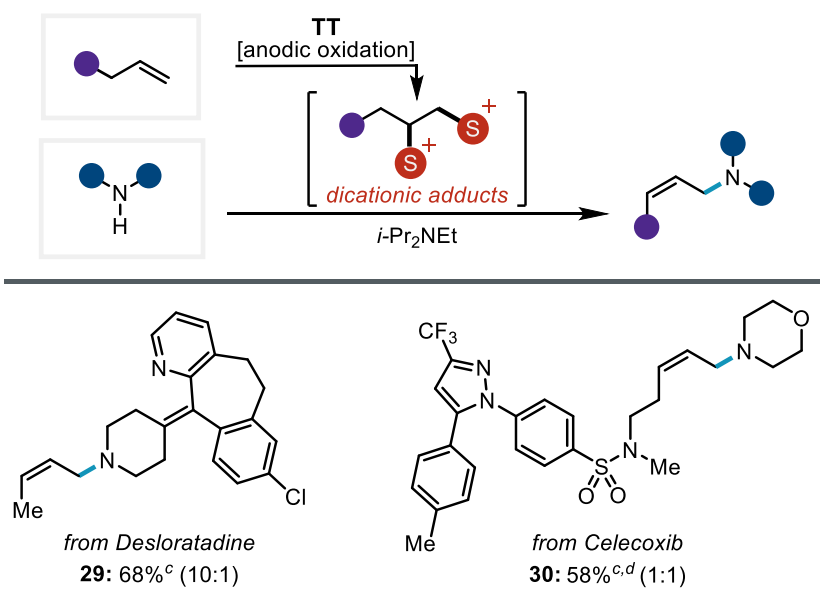

29: $68 \%^{c}(10: 1)$

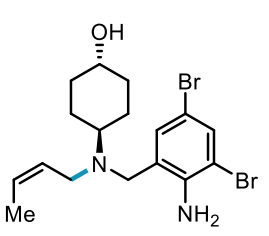

$\mathrm{Me}$

from Ambroxol

from Carvedilo

31: $56 \%(10: 1)$

32: $34 \%{ }^{c}(8: 1)$
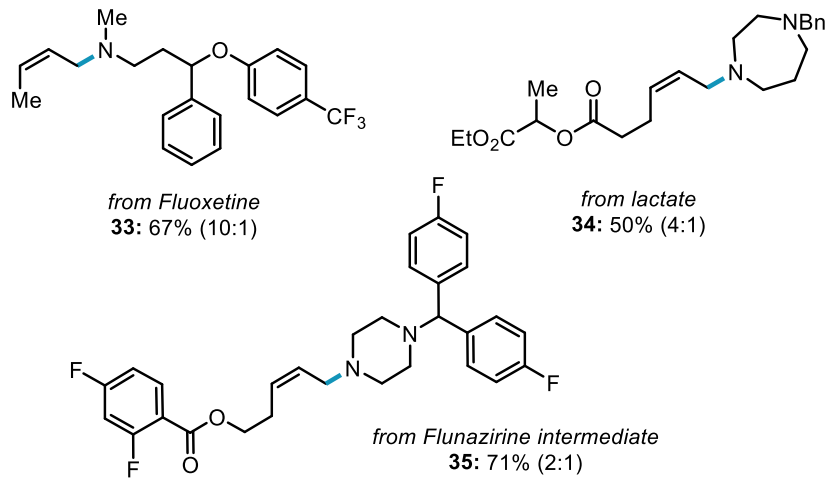

aLimiting amine reactions were conducted using alkene (1 atm), TT (1.0 mmol),

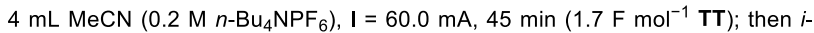
$\mathrm{Pr}_{2} \mathrm{NEt}(3.2 \mathrm{mmol})$, amine $(0.4 \mathrm{mmol}), 3 \mathrm{~h}$. Limiting alkene reactions were conducted using alkene $(0.4 \mathrm{mmol}), \mathrm{TT}(0.6 \mathrm{mmol}), 8 \mathrm{~mL} \operatorname{MeCN}(0.2 \mathrm{M} \mathrm{n}$ -

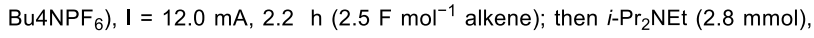
amine $(0.4 \mathrm{mmol}), 16 \mathrm{~h}$. Yields and $Z$ : $E$ ratios are of the purified product unless otherwise noted. See the SI for further details. ${ }^{b}$ Isolated yield (Z:E). ${ }^{c}$ NMR yield. ${ }^{d} 0.8 \mathrm{mmol}$ amine.

like compounds as both alkene and amine coupling partners. Due to their structural complexity, these substrates each contain numerous functional groups expected to be labilities for typical oxidative allylic amination procedures. Lewis basic heterocycles, such as pyridine (29) and pyrazole (30) as well as oxidatively sensitive electron-rich aromatic systems (3133), ${ }^{25}$ each delivered the desired allylic amine products. Additionally, allylic amines could be obtained from substrates bearing a variety of saturated heterocycles, including piperidine (29), morpholine (30), homopiperazine (34), and piperizine (35). Of note, the homopiperazine (34) and piperizine substrates $(\mathbf{3 5})$, each contain a competent tertiary amine nucleophile yet produce the desired allylic amine products in synthetically useful yield. This chemoselectivity extended to other nucleophilic functional groups; unprotected alcohols and arylamines $(\mathbf{3 1}, \mathbf{3 2})$ did not compete with the secondary amine under these allylation conditions, leaving them as synthetic

handles for further functionalization. An array of different aryl halides were well tolerated, including both medicinally relevant fluorinated groups $(\mathbf{3 0}, \mathbf{3 3}, \mathbf{3 5})$ as well as aryl bromides (32) and chlorides (29) that readily participate in crosscoupling reactions.

Next, we aimed to provide some preliminary mechanistic insight into this new process. Monitoring the transformation of dicationic adducts to allylic amine over time revealed that the adducts are rapidly consumed and a vinylthianthrenium salt is generated. Given the basic conditions, we suspected that the vinylthianthrenium salt was likely a key intermediate en route to the observed allylic amine product rather than an off-cycle reservoir. To probe this specific question, we directly prepared vinylthianthrenium salt $\mathbf{3 6}$ by baseinduced elimination of the electrochemically generated dicationic adducts between 1-butene and thianthrene. We then subjected this isolated vinylthianthrenium $\mathbf{3 6}$ to otherwise standard substitution conditions (see SI for experimental details). Under these conditions, the allyic amine product 19 was formed in $75 \%$ yield and identical stereoselectivity to what is observed under standard conditions (Eq. 1). This is consistent with the vinyl thianthrenium salt serving as an on pathway intermediate. Based on these data, we have constructed a working mechanistic model wherein the vinylthianthrenium salt undergoes a base-induced isomerization to an allylic thianthrenium intermediate. This species is then rapidly trapped with the amine nucleophile. Indeed, there is a single report of vinylsulfonium salts being converted to allylic amines. ${ }^{95}$ Studies are underway to clarify the mechanistic details of this reaction, particularly the stereodetermining step for the process. Beyond the mechanistic implications, however, these data also indicate that vinylthianthrenium salts prepared through chemical means ${ }^{77}$ can be engaged as an electrophile for this transformation. We envision this may be valuable for practicing synthetic chemists in a small-scale research and development setting where electrochemistry offers a less significant advantage relative to more traditional synthetic tactics.
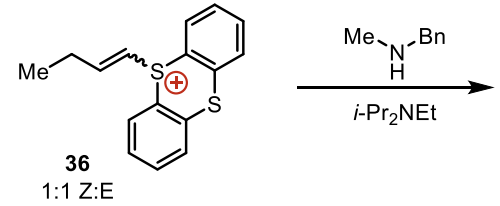

Overall, we developed an electrochemical synthesis of allylic amines from terminal alk enes and secondary amines. This represents the first example of a formal $\mathrm{C}-\mathrm{H}$ functionalization approach to furnish tertiary aliphatic allylic amines as well as the first example of a strategy for Zselective oxidative allylic $\mathrm{C}-\mathrm{H}$ functionalization. This linearselective process exhibits good functional group tolerance and is attractive for substrates ranging from feedstock gas functionalization to derivatization of complex molecules. Furthermore, the conditions are operationally simple; no precautions to exclude air or moisture are necessary. Preliminary mechanistic studies indicate that vinylthianthrenium salts are key intermediates. We anticipate that this new electrochemical transformation will find immediate application in organic synthesis given the established synthetic utility of allylic amine building blocks. Moreover, we anticipate that the results reported herein set the stage for the development of a wide range of Z-selective allylic functionalization reactions that remain challenging to accomplish via more conventional approaches. 


\section{ASSOCIATED CONTENT}

\section{Supporting Information}

The Supporting Information is available free of charge on the ACS Publications website.

Experimental procedures, characterization data, and spectra (PDF)

\section{AUTHOR INFORMATION}

\section{Corresponding Author}

* Zachary K. Wickens - Department of Chemistry, University of Wisconsin-Madison, Madison, Wisconsin 53706, United States; orcid.org/0000-0002-5733-5288; Email: wickens@ wisc.edu

\section{Author Contributions}

Diana J. Wang - Department of Chemistry, University of Wisconsin-Madison, Madison, Wisconsin 53706, United States; orcid.org/0000-0003-3790-0240

Karina Targos - Department of Chemistry, University of Wisconsin-Madison, Madison, Wisconsin 53706, United States; orcid.org/0000-0002-9945-0719

\section{Notes}

The authors declare no competing financial interest.

\section{ACKNOWLEDGMENT}

We thank Prof. Mark Levin for helpful discussions regarding this manuscript. We thank the Weix, Stahl, Yoon and Schomaker groups for sharing their chemical inventories. In addition, we would like to thank Sam Gellman and the entire Gellman group for hosting the authors of this work during a temporary closure of our labs. Along this line, we also thank the staff of the Paul Bender Chemistry Instrumentation Center for enabling NMR and MS sample analysis during building construction. B. J. Thompson is acknowledged for his assistance with the design and fabrication of the power supply. T. Drier is acknowledged for the fabrication of electrochemical glassware. We also acknowledge support and suggestions from all members of the Wickens group throughout the investigation of this project. This work was financially supported by the Office of the Vice Chancellor for Research and Graduate Education at the University of Wisconsin-Madison, with funding from the Wisconsin Alumni Research Foundation. This material is based upon work supported by the National Science Foundation Graduate Research Fellowship Program under Grant No. DGE-1747503 (K.T.). Any opinions, findings, and conclusions or recommendations expressed in this material are those of the author(s) and do not necessarily reflect the views of the $\mathrm{Na}$ tional Science Foundation. Spectroscopic instrumentation was supported by a generous gift from Paul J. and Margaret M. Bender, the National Science Foundation (CHE-1048642), and the National Institutes of Health (S10OD012245 and 1S10OD020022-1)

\section{REFERENCES}

Trowbridge, A.; Walton, S. M.; Gaunt, M. J. New Strategies for the Transition-Metal Catalyzed Synthesis of Aliphatic Amines. Chem. Rev. 2020, 120 (5), 2613-2692. https://doi.org/10.1021/acs.chemrev.9b00462. Compound Accumulation Rules Yield a Broad-Spectrum

Antibiotic. Nature 2017, 545 (7654), 299-304. https://doi.org/10.1038/nature22308.

Vitaku, E.; Smith, D. T.; Njardarson, J. T. Analysis of the Structural Diversity, Substitution Patterns, and Frequency of Nitrogen Heterocycles among U.S. FDA Approved Pharmaceuticals. J. Med. Chem. 2014, 57 (24), 1025710274. https://doi.org/10.1021/jm501100b.

(4) For examples of synthetic strategies that exploit allylic amines as key intermediates, see references 5-8.

Johannsen, M.; Jørgensen, K. A. Allylic Amination. Chem. Rev. 1998, 98 (4), 1689-1708. https://doi.org/10.1021/cr970343o.

(6) Wang, M.; Xiao, F.; Bai, Y.; Hu, X. Reactions of Tertiary Allylic Amines and Dichlorocarbenes. Synth. Commun. 2015, $45 \quad$ (19), 2259-2265. https://doi.org/10.1080/00397911.2015.1075218.

(7) DeLuca, R. J.; Sigman, M. S. Anti-Markovnikov Hydroalkylation of Allylic Amine Derivatives via a Palladium-Catalyzed Reductive Cross-Coupling Reaction. J. Am. Chem. Soc. 2011, 133 (30), 11454-11457. https://doi.org/10.1021/ja204080s.

(8) Weiner, B.; Baeza, A.; Jerphagnon, T.; Feringa, B. L. Aldehyde Selective Wacker Oxidations of Phthalimide Protected Allylic Amines: A New Catalytic Route to B3Amino Acids. J. Am. Chem. Soc. 2009, 131 (27), 94739474. https://doi.org/10.1021/ja902591g.

Allylic $\mathrm{S}_{\mathrm{N}} 2$ can suffer from numerous problems such as poor regioselectivity between branched and linear products and over-allylation. For specific examples, see references 11-13.

(10) For selected successful examples of $S_{\mathrm{N}} 2$-type allylationreactions, see references 14-16.

(11) Mitsunobu, O. Comprehensive Organic Synthesis. In Comprehensive Organic Synthesis; Trost, B. M., Fleming, I.; Pergamon: Oxford, 1991.

(12) Sen, S. E.; Roach, S. L. A Convenient Two-Step Procedure for the Synthesis of Substituted Allylic Amines from Allylic Alcohols. Synthesis 1995, 1995 (07), 756-758. https://doi.org/10.1055/s-1995-4012.

(13) Solomons, G.; Fryhle, C. Organic Chemistry; Wiley: New York, 2000.

(14) Roughley, S. D.; Jordan, A. M. The Medicinal Chemist's Toolbox: An Analysis of Reactions Used in the Pursuit of Drug Candidates. J. Med. Chem. 2011, 54 (10), 34513479. https://doi.org/10.1021/jm200187y.

(15) Brown, D. G.; Boström, J. Analysis of Past and Present Synthetic Methodologies on Medicinal Chemistry: Where Have All the New Reactions Gone?: Miniperspective. J. Med. Chem. 2016, 59 (10), 4443-4458. https://doi.org/10.1021/acs.jmedchem.5b01409.

(16) Taylor, A. R.; Katritzky, R. J. K. Comprehensive Organic Functional Group Transformations II. In Comprehensive Organic Functional Group Transformations II.; Elsevier; pp 255-300.

(17) For further discussions of amination of transition metal $\pi$-allyl intermediates derived from allylic electrophiles, see references 18-24.

(18) Trost, B. M.; Van Vranken, D. L. Asymmetric Transition Metal-Catalyzed Allylic Alkylations. Chem. Rev. 1996, 96 (1), 395-422. https://doi.org/10.1021/cr9409804.

(19) Graening, T.; Schmalz, H.-G. Pd-Catalyzed Enantioselective Allylic Substitution: New Strategic Options for the Total Synthesis of Natural Products. Angew. Chem. Int. Ed. 2003, 42 (23), 2580-2584. https://doi.org/10.1002/anie.200301644. 
(20) Grange, R. L.; Clizbe, E. A.; Evans, P. A. Recent Developments in Asymmetric Allylic Amination Reactions. Synthesis 2016, 58.

(21) Yamashita, Y.; Gopalarathnam, A.; Hartwig, J. F. Iridium-Catalyzed, Asymmetric Amination of Allylic Alcohols Activated by Lewis Acids. J. Am. Chem. Soc. 2007, 129 (24), 7508-7509. https://doi.org/10.1021/ja0730718.

(22) You, S.-L.; Zhu, X.-Z.; Luo, Y.-M.; Hou, X.-L.; Dai, L.$\mathrm{X}$. Highly Regio- and Enantioselective Pd-Catalyzed Allylic Alkylation and Amination of Monosubstituted Allylic Acetates with Novel Ferrocene P,N-Ligands. J. Am. Chem. Soc. 2001, 123 (30), 7471-7472. https://doi.org/10.1021/ja016121w.

(23) Takeuchi, R.; Ue, N.; Tanabe, K.; Yamashita, K.; Shiga, N. Iridium Complex-Catalyzed Allylic Amination of Allylic Esters. J. Am. Chem. Soc. 2001, 123 (39), 95259534. https://doi.org/10.1021/ja0112036.

(24) Sundararaju, B.; Achard, M.; Bruneau, C. Transition Metal Catalyzed Nucleophilic Allylic Substitution: Activation of Allylic Alcohols via $\pi$-Allylic Species. Chem. Soc. Rev. 2012, $41 \quad$ (12), 4467-4483. https://doi.org/10.1039/C2CS35024F.

(25) Roth, H.; Romero, N.; Nicewicz, D. Experimental and Calculated Electrochemical Potentials of Common Organic Molecules for Applications to Single-Electron Redox Chemistry. Synlett 2015, 27 (05), 714-723. https://doi.org/10.1055/s-0035-1561297.

(26) Cheng, Q.; Chen, J.; Lin, S.; Ritter, T. Allylic Amination of Alkenes with Iminothianthrenes to Afford Alkyl Allylamines. J. Am. Chem. Soc. 2020, 142 (41), $17287-$ 17293. https://doi.org/10.1021/jacs.0c08248.

(27) Substantial progress has been made in redox-neutral hydroamination processes that furnish aliphatic amine products. See references 28-35.

(28) Wiese, S.; Badiei, Y. M.; Gephart, R. T.; Mossin, S.; Varonka, M. S.; Melzer, M. M.; Meyer, K.; Cundari, T. R.; Warren, T. H. Catalytic CóH Amination with Unactivated Amines through Copper(II) Amides. Angew. Chem. Int. Ed. 2010, 49 (47), 8850-8855. https://doi.org/10.1002/anie.201003676.

(29) Beller, M.; Trauthwein, H.; Eichberger, M.; Breindl, C.; Herwig, J.; Müller, T. E.; Thiel, O. R. The First Rhodium-Catalyzed Anti-Markovnikov Hydroamination: Studies on Hydroamination and Oxidative Amination of $\mathrm{Ar}$ omatic Olefins. Chem. - Eur. J. 1999, 5 (4), 1306-1319. https://doi.org/10.1002/(SICI)1521-

3765(19990401)5:4<1306::AID-CHEM1306>3.0.CO;24.

(30) Utsunomiya, M.; Hartwig, J. F. Intermolecular, Markovnikov Hydroamination of Vinylarenes with Alkylamines. J. Am. Chem. Soc. 2003, 125 (47), 14286-14287. https://doi.org/10.1021/ja0375535.

(31) Al-Masum, M.; Meguro, M.; Yamamoto, Y. The Two Component Palladium Catalyst System for Intermolecular Hydroamination of Allenes. Tetrahedron Lett. 1997, 38 (34), 6071-6074. https://doi.org/10.1016/S00404039(97)01370-1.

(32) Kuchenbeiser, G.; Shaffer, A. R.; Zingales, N. C.; Beck, J. F.; Schmidt, J. A. R. Palladium(II) 3-Iminophosphine (3IP) Complexes: Active Precatalysts for the Intermolecular Hydroamination of 1,2-Dienes (Allenes) and 1,3Dienes with Aliphatic Amines under Mild Conditions. $J$. Organomet. Chem. 2011, 696 (1), 179-187. https://doi.org/10.1016/j.jorganchem.2010.08.033.

(33) Ickes, A. R.; Ensign, S. C.; Gupta, A. K.; Hull, K. L. Regio- and Chemoselective Intermolecular Hydroamina- tion of Allyl Imines for the Synthesis of 1,2-Diamines. $J$. Am. Chem. Soc. 2014, 136 (32), 11256-11259. https://doi.org/10.1021/ja505794u.

(34) Liu, R. Y.; Buchwald, S. L. CuH-Catalyzed Olefin Functionalization: From Hydroamination to Carbonyl Addition. Acc. Chem. Res. 2020, 53 (6), 1229-1243. https://doi.org/10.1021/acs.accounts.0c00164.

(35) Gui, J.; Pan, C.-M.; Jin, Y.; Qin, T.; Lo, J. C.; Lee, B. J.; Spergel, S. H.; Mertzman, M. E.; Pitts, W. J.; La Cruz, T. E.; Schmidt, M. A.; Darvatkar, N.; Natarajan, S. R.; Baran, P. S. Practical Olefin Hydroamination with Nitroarenes. Science 2015, 348 (6237), 886-891. https://doi.org/10.1126/science.aab0245.

(36) Ramirez, T. A.; Zhao, B.; Shi, Y. Recent Advances in Transition Metal-Catalyzed Sp3 C-H Amination Adjacent to Double Bonds and Carbonyl Groups. Chem. Soc. $\begin{array}{llll}\text { Rev. } & \text { 2012, } & 41 & \text { (2), }\end{array}$ https://doi.org/10.1039/C1CS15104E.

(37) Liron, F.; Oble, J.; Lorion, M. M.; Poli, G. Direct Allylic Functionalization Through Pd-Catalyzed C-H Activation: Direct Allylic Functionalization by Pd-Catalyzed C-H Activation. Eur. J. Org. Chem. 2014, 2014 (27), 5863 5883. https://doi.org/10.1002/ejoc.201402049.

(38) Fernandes, R. A.; Nallasivam, J. L. Catalytic Allylic Functionalization via $\pi$-Allyl Palladium Chemistry. Org. Biomol. Chem. 2019, 17 (38), 8647-8672. https://doi.org/10.1039/C9OB01725A.

(39) Wang, R.; Luan, Y.; Ye, M. Transition Metal-Catalyzed Allylic C(Sp3)-H Functionalization via H3-Allylmetal Intermediate. Chin. J. Chem. 2019, 37 (7), 720-743. https://doi.org/10.1002/cjoc.201900140.

(40) Burman, J. S.; Blakey, S. B. Regioselective Intermolecular Allylic C-H Amination of Disubstituted Olefins via Rhodium/П-Allyl Intermediates. Angew. Chem. Int. Ed. 2017, $56 \quad$ (44), 13666-13669. https://doi.org/10.1002/anie.201707021.

(41) Ma, R.; White, M. C. C-H to C-N Cross-Coupling of Sulfonamides with Olefins. J. Am. Chem. Soc. 2018, 140 (9), 3202-3205. https://doi.org/10.1021/jacs.7b13492.

(42) Lei, H.; Rovis, T. Ir-Catalyzed Intermolecular BranchSelective Allylic C-H Amidation of Unactivated Terminal Olefins. J. Am. Chem. Soc. 2019, 141 (6), 2268-2273. https://doi.org/10.1021/jacs.9b00237.

(43) Liu, G.; Yin, G.; Wu, L. Palladium-Catalyzed Intermolecular Aerobic Oxidative Amination of Terminal Alkenes: Efficient Synthesis of Linear Allylamine Derivatives. Angew. Chem. Int. Ed. 2008, 47 (25), 4733-4736. https://doi.org/10.1002/anie.200801009.

(44) Reed, S. A.; Mazzotti, A. R.; White, M. C. A Catalytic, Brønsted Base Strategy for Intermolecular Allylic C-H Amination. J. Am. Chem. Soc. 2009, 131 (33), 1170111706. https://doi.org/10.1021/ja903939k.

(45) Pattillo, C. C.; Strambeanu, I. I.; Calleja, P.; Vermeulen, N. A.; Mizuno, T.; White, M. C. Aerobic Linear Allylic C-H Amination: Overcoming Benzoquinone Inhibition. J. Am. Chem. Soc. 2016, 138 (4), 1265-1272. https://doi.org/10.1021/jacs.5b11294.

(46) Yin, G.; Wu, Y.; Liu, G. Scope and Mechanism of Allylic $\mathrm{C}-\mathrm{H}$ Amination of Terminal Alkenes by the Palladium/PhI(OPiv)2 Catalyst System: Insights into the Effect of Naphthoquinone. J. Am. Chem. Soc. 2010, 132 (34), 11978-11987. https://doi.org/10.1021/ja1030936.

(47) Harris, R. J.; Park, J.; Nelson, T. A. F.; Iqbal, N.; Salgueiro, D. C.; Bacsa, J.; MacBeth, C. E.; Baik, M.-H.; Blakey, S. B. The Mechanism of Rhodium-Catalyzed Al- 
lylic C-H Amination. J. Am. Chem. Soc. 2020, 142 (12), 5842-5851. https://doi.org/10.1021/jacs.0c01069.

(48) Lei, H.; Rovis, T. A Site-Selective Amination Catalyst Discriminates between Nearly Identical $\mathrm{C}-\mathrm{H}$ Bonds of Unsymmetrical Disubstituted Alkenes. Nat. Chem. 2020, 12 (8), 725-731. https://doi.org/10.1038/s41557-0200470-z.

(49) Ide, T.; Feng, K.; Dixon, C. F.; Teng, D.; Clark, J. R.; Han, W.; Wendell, C. I.; Koch, V.; White, M. C. LateStage Intermolecular Allylic $\mathrm{C}-\mathrm{H}$ Amination. J. Am. Chem. Soc. 2021, jacs.1c06335. https://doi.org/10.1021/jacs.1c06335.

(50) Gephart III, R. T.; Huang, D. L.; Aguila, M. J. B.; Schmidt, G.; Shahu, A.; Warren, T. H. Catalytic Cón Amination with Aromatic Amines. Angew. Chem. Int. Ed. 2012, $51 \quad$ (26), 6488-6492. https://doi.org/10.1002/anie.201201921.

(51) Roizen, J. L.; Harvey, M. E.; Du Bois, J. Metal-Catalyzed Nitrogen-Atom Transfer Methods for the Oxidation of Aliphatic C-H Bonds. Acc. Chem. Res. 2012, 45 (6), 911-922. https://doi.org/10.1021/ar200318q.

(52) Starkov, P.; Jamison, T. F.; Marek, I. Electrophilic Amination: The Case of Nitrenoids. Chem. - Eur. J. 2015, 21 (14), $5278-5300$. https://doi.org/10.1002/chem.201405779.

(53) Dauban, P.; Dodd, R. H. Iminoiodanes and C-NBond Formation in Organic Synthesis. Synlett 2003, 2003 (11), 1571-1586. https://doi.org/10.1055/s-2003-41010.

(54) Shimbayashi, T.; Sasakura, K.; Eguchi, A.; Okamoto, K.; Ohe, K. Recent Progress on Cyclic Nitrenoid Precursors in Transition-Metal-Catalyzed Nitrene-Transfer Reactions. Chem. - Eur. J. 2019, 25 (13), 3156-3180. https://doi.org/10.1002/chem.201803716.

(55) Scriven, E. F. V.; Turnbull, K. Azides: Their Preparation and Synthetic Uses. Chem. Rev. 1988, 88 (2), 297-368. https://doi.org/10.1021/cr00084a001.

(56) Shin, K.; Kim, H.; Chang, S. Transition-Metal-Catalyzed $\mathrm{C}-\mathrm{N}$ Bond Forming Reactions Using Organic Azides as the Nitrogen Source: A Journey for the Mild and Versatile C-H Amination. Acc. Chem. Res. 2015, 48 (4), 10401052. https://doi.org/10.1021/acs.accounts.5b00020.

(57) Lebel, H.; Huard, K.; Lectard, S. N-Tosyloxycarbamates as a Source of Metal Nitrenes: Rhodium-Catalyzed C-H Insertion and Aziridination Reactions. J. Am. Chem. Soc. 2005, 127 (41), 14198-14199. https://doi.org/10.1021/ja0552850.

(58) Hennessy, E. T.; Betley, T. A. Complex N-Heterocycle Synthesis via Iron-Catalyzed, Direct C-H Bond Amination. Science 2013, 340 (6132), 591-595. https://doi.org/10.1126/science.1233701.

(59) Hennessy, E. T.; Liu, R. Y.; Iovan, D. A.; Duncan, R. A.; Betley, T. A. Iron-Mediated Intermolecular N-Group Transfer Chemistry with Olefinic Substrates. Chem. Sci. 2014, 5 (4), 1526-1532. https://doi.org/10.1039/C3SC52533C.

(60) Liang, C.; Collet, F.; Robert-Peillard, F.; Müller, P.; Dodd, R. H.; Dauban, P. Toward a Synthetically Useful Stereoselective C-H Amination of Hydrocarbons. J. Am. Chem. Soc. 2008, 130 (1), 343-350. https://doi.org/10.1021/ja076519d.

(61) Collet, F.; Lescot, C.; Liang, C.; Dauban, P. Studies in Catalytic C-H Amination Involving Nitrene C-H Insertion. Dalton Trans. 2010, 39 (43), 10401-10413. https://doi.org/10.1039/C0DT00283F.

(62) Fantauzzi, S.; Gallo, E.; Caselli, A.; Ragaini, F.; Casati, N.; Macchi, P.; Cenini, S. The Key Intermediate in the
Amination of Saturated C-H Bonds: Synthesis, X-Ray Characterization and Catalytic Activity of $\mathrm{Ru}(\mathrm{TPP})(\mathrm{NAr}) 2$ ( $\mathrm{Ar}=3,5-(\mathrm{CF} 3) 2 \mathrm{C} 6 \mathrm{H} 3)$. Chem. Commun. 2009, No. 26, 3952-3954. https://doi.org/10.1039/B903238J.

(63) Leveraging ene reactions rather than nitrene insertion, other high oxidation state nitrogen sources have been used for allylic amination. See references 64-65.

(64) Bao, H.; Tambar, U. K. Catalytic Enantioselective Allylic Amination of Unactivated Terminal Olefins via an Ene Reaction/[2,3]-Rearrangement. J. Am. Chem. Soc. 2012, 134 (45), 18495-18498. https://doi.org/10.1021/ja307851b.

(65) Bayeh, L.; Le, P. Q.; Tambar, U. K. Catalytic Allylic Oxidation of Internal Alkenes to a Multifunctional Chiral Building Block. Nature 2017, 547 (7662), 196-200. https://doi.org/10.1038/nature22805.

(66) New strategies for alkene oxidation strategies towards Nalkyl aziridine synthesis has been recently developed, see ref 67-71. In stark contrast, the synthesis of allylic amine building blocks from alkenes via net $\mathrm{C}\left(\mathrm{sp}^{3}\right)-\mathrm{H}$ amination transformations remains limited.

(67) Falk, E.; Makai, S.; Delcaillau, T.; Gürtler, L.; Morandi, B. Design and Scalable Synthesis of $N$ -Alkylhydroxylamine Reagents for the Direct Iron-Catalyzed Installation of Medicinally Relevant Amines**. Angew. Chem. Int. Ed. 2020, 59 (47), 21064 21071. https://doi.org/10.1002/anie.202008247.

(68) Jat, J. L.; Paudyal, M. P.; Gao, H.; Xu, Q.-L.; Yousufuddin, M.; Devarajan, D.; Ess, D. H.; Kürti, L.; Falck, J. R. Direct Stereospecific Synthesis of Unprotected N-H and N-Me Aziridines from Olefins. Science 2014, 343 (6166), 61-65. https://doi.org/10.1126/science.1245727.

(69) Ošeka, M.; Laudadio, G.; Leest, N. P. van; Dyga, M.; Bartolomeu, A. de A.; Gooßen, L. J.; Bruin, B. de; Oliveira, K. T. de; Noël, T. Electrochemical Aziridination of Internal Alkenes with Primary Amines. Chem 2021, 7 (1), 255-266. https://doi.org/10.1016/j.chempr.2020.12.002.

(70) Govaerts, S.; Angelini, L.; Hampton, C.; Malet-Sanz, L.; Ruffoni, A.; Leonori, D. Photoinduced Olefin Diamination with Alkylamines. Angew. Chem. Int. Ed. 2020, 59 (35), $15021-15028$ https://doi.org/10.1002/anie.202005652.

(71) Holst, D. E.; Wang, D. J.; Kim, M. J.; Guzei, I. A.; Wickens, Z. K. Aziridine Synthesis by Coupling Amines and Alkenes via an Electrogenerated Dication. Nature 2021, 596 (7870), 74-79. https://doi.org/10.1038/s41586021-03717-7.

(72) 2,490,000 primary amines and 1,888,500 secondary amines, which totals $4,378,500$ commerical amines to give aliphatic amine products. eMolecules (eMolecules Inc, accessed 7 November 2021); https://www.emolecules.com.

(73) Yoshida, J.; Shimizu, A.; Hayashi, R. Electrogenerated Cationic Reactive Intermediates: The Pool Method and Further Advances. Chem. Rev. 2018, 118 (9), 4702-4730. https://doi.org/10.1021/acs.chemrev.7b00475.

(74) Hayashi, R.; Shimizu, A.; Yoshida, J. The Stabilized Cation Pool Method: Metal- and Oxidant-Free Benzylic C-H/Aromatic C-H Cross-Coupling. J. Am. Chem. Soc. 2016, 138 (27), 8400-8403. https://doi.org/10.1021/jacs.6b05273.

(75) Yoshida, J.; Suga, S. Basic Concepts of "Cation Pool" and "Cation Flow" Methods and Their Applications in Conventional and Combinatorial Organic Synthesis. 
Chem. - Eur. J. 2002, 8 (12), 2650-2658. https://doi.org/10.1002/15213765(20020617)8:12<2650::AID-CHEM2650>3.0.CO;2$\mathrm{S}$.

(76) Berger, F.; Plutschack, M. B.; Riegger, J.; Yu, W.; Speicher, S.; Ho, M.; Frank, N.; Ritter, T. Site-Selective and Versatile Aromatic C-H Functionalization by Thianthrenation. Nature 2019, 567 (7747), 223-228. https://doi.org/10.1038/s41586-019-0982-0.

(77) Chen, J.; Li, J.; Plutschack, M. B.; Berger, F.; Ritter, T. Regio- and Stereoselective Thianthrenation of Olefins To Access Versatile Alkenyl Electrophiles. Angew. Chem. Int. $\quad E d . \quad \mathbf{2 0 2 0}, \quad 59$ (14), 5616-5620. https://doi.org/10.1002/anie.201914215.

(78) Alvarez, E. M.; Plutschack, M. B.; Berger, F.; Ritter, T. Site-Selective $\mathrm{C}-\mathrm{H}$ Functionalization-Sulfination Sequence to Access Aryl Sulfonamides. Org. Lett. 2020, acs.orglett.0c00982.

https://doi.org/10.1021/acs.orglett.0c00982.

(79) Juliá, F.; Yan, J.; Paulus, F.; Ritter, T. Vinyl Thianthrenium Tetrafluoroborate: A Practical and Versatile Vinylating Reagent Made from Ethylene. J. Am. Chem. Soc. 2021, jacs.1c06632. https://doi.org/10.1021/jacs.1c06632.

(80) Chen, C.; Wang, M.; Lu, H.; Zhao, B.; Shi, Z. Enabling the Use of Alkyl Thianthrenium Salts in Cross-Coupling Reactions by Copper Catalysis. Angew. Chem. Int. Ed. 2021, 60 (40), 21756-21760. https://doi.org/10.1002/anie.202109723.

(81) Chen, C.; Wang, Z.-J.; Lu, H.; Zhao, Y.; Shi, Z. Generation of Non-Stabilized Alkyl Radicals from Thianthrenium Salts for C-B and C-C Bond Formation. Nat. Commun. 2021, 12 (1), 4526. https://doi.org/10.1038/s41467021-24716-2.

(82) Jia, H.; Häring, A. P.; Berger, F.; Zhang, L.; Ritter, T. Trifluoromethyl Thianthrenium Triflate: A Readily Available Trifluoromethylating Reagent with Formal CF3+, CF3•, and CF3- Reactivity. J. Am. Chem. Soc. 2021, 143 (20), 7623-7628. https://doi.org/10.1021/jacs.1c02606.

(83) Antoni, P. W.; Mackenroth, A. V.; Mulks, F. F.; Rudolph, M.; Helmchen, G.; Hashmi, A. S. K. Dibenzothiophenesulfilimines: A Convenient Approach to Intermolecular Rhodium-Catalysed C-H Amidation. Chem. Eur. J. 2020, $26 \quad$ (37), 8235-8238. https://doi.org/10.1002/chem.202002371.

(84) Shine, H. J.; Bandlish, B. K.; Mani, S. R.; Padilla, A. G. Ion Radicals. 43. Addition of Thianthrene and Phenoxathiin Cation Radicals to Alkenes and Alkynes. J. Org.
Chem. 1979, $44 \quad$ (6), 915-917. https://doi.org/10.1021/jo01320a004.

Shine, H. J.; Zhao, B.; Qian, D.-Q.; Marx, J. N.; GuzmanJimenez, I. Y.; Thurston, J. H.; Ould-Ely, T.; Whitmire, K. H. Adducts of Phenoxathiin and Thianthrene Cation Radicals with Alkenes and Cycloalkenes. J. Org. Chem. 2003, 68 (23), 8910-8917. https://doi.org/10.1021/jo030173h.

(86) Mitchell, S. C.; Waring, R. H. Fate of Thianthrene in Biological Systems. Xenobiotica 2017, 47 (8), 731-740. https://doi.org/10.1080/00498254.2016.1222107.

(87) The cost of thianthrene is less than 0.15 USD mmol-1.

(88) Alkyne thianthrenation by chemically generated thianthrene radical cation has been previously observed, see: Rangappa, P.; Shine, H. J.; Marx, J. N.; Ould-Ely, T.; Kelly, A. T.; Whitmire, K. H. Adducts of Thianthrene- and Phenoxathiin Cation Radical Tetrafluoroborates to 1-Alkynes. Structures and Formation of 1-(5Thianthreniumyl)- and 1-(10-Phenoxathiiniumyl)Alkynes on Alumina Leading to $\alpha$-Ketoylides and $\alpha$-Ketols. $J$. Org. Chem. 2005, 70 (24), 9764-9770. https://doi.org/10.1021/jo051317q.

(89) While stereoselectivity was attenuated in these examples bearing proximal branching or functional groups, the thermodynami-cally disfavored Z-isomer was still observed.

(90) Currently, this methodology is restricted to terminal alkenes. While adduct could be formed readily from internal alkenes, these adducts provided an intractable mixture upon treatment with the amine nucleophile (see SI for details).

(91) Zimmermann, H. Propene. In Ullmann's Encyclopedia of Industrial Chemistry; American Cancer Society, 2013; pp 00-00. https://doi.org/10.1002/14356007.a22_211.pub3.

(92) Geilen, F. M. A.; Stochniol, G.; Peitz, S.; SchulteKoerne, E. Butenes. In Ullmann's Encyclopedia of Industrial Chemistry; American Cancer Society, 2014; pp 113. https://doi.org/10.1002/14356007.a04_483.pub3.

(93) Krähling, L.; Krey, J.; Jakobson, G.; Grolig, J.; Miksche, L. Allyl Compounds. In Ullmann's Encyclopedia of Industrial Chemistry; American Cancer Society, 2000. https://doi.org/10.1002/14356007.a01_425.

(94) Our previous report shows $76 \%$ thianthrene recovery following substitution of the dicationic adducts upon scaleup. See reference 71 .

(95) Yamanaka, H.; Matsuo, J.; Kawana, A.; Mukaiyama, T. A Convenient Method for the Synthesis of $\beta, \gamma$ Unsaturated Amines from Alkenes via $\alpha, \beta$-Unsaturated Diphenylsulfonium Salts. Chem. Lett. 2003, 32 (7), 626627. https://doi.org/10.1246/cl.2003.626. 